\title{
RELATO DE UM PROJETO INTERDISCIPLINAR COM ADOLESCENTES NO ENSINO MÉDIO: UMA APROXIMAÇÃO AO EXERCÍCIO DA AÇÃO DEMOCRÁTICA+
}

\author{
NOTES FROM AN INTERDISCIPLINARY PROJECT WITH \\ ADOLESCENTS IN THE HIGH SCHOOL: AN APPROACH TO \\ AN EXERCISE TO A DEMOCRATIC ACTION \\ Maria Aparecida Conti ${ }^{*}$ \\ André Castelani ${ }^{* *}$ \\ Denilson Battistini ${ }^{* * *}$
}

Conti MA, Castelani A, Battistini D. Relato de um projeto com adolescentes no ensino médio: uma aproximação ao exercício da ação democrática. Rev Bras Cresc Desenv Hum 2005; 15(3):69-73.

\begin{abstract}
Resumo: O conceito de cidadania entendido como o gozo de direitos e desempenho de deveres, de comprometimento com a realidade social e com a sua transformação, inicia-se quando direitos e deveres passam a ser percebido como dois lados da mesma moeda. Isso torna-se possível quando jovens, saindo de uma posição passiva, passam a assumir o seu papel como agentes de mudança social. A equipe de professores de uma Escola da Rede Particular de Ensino, integrando nas intenções pedagógicas de seu currículo a educação política, desenvolveu um estudo de campo envolvendo a conceituação de cidadania e democracia, que culminou com o desenvolvimento de atividades na Câmara dos Vereadores do município de Santo André. Cerca de 100 alunos da $1^{\text {a }}$ série do Ensino Médio participaram ativamente da sessão da Câmara, conhecendo a rotina do poder legislativo municipal, por meio do exercício democrático, considerado como base fundamental para a educação política. Desta forma, a equipe de professores pode cumprir uma das metas principais: a educação cidadã. $\mathrm{O}$ aluno teve contato com a teoria política e análise de sua realidade social imediata, descobrindo a necessidade de participação social e política consciente e de sua responsabilidade social frente às demandas em uma sociedade em constante transformação.
\end{abstract}

Palavras-chave: Projeto interdisciplinar. Educação política. Educação cidadã.

\section{Contextualizando nosso cenário}

O conceito de cidadania - como um indivíduo no gozo de seus direitos e desempenho dos deveres, como um cidadão capaz de comprometer-se com a realidade social e com a sua transformação - , inicia-se quando direitos e deveres passam a ser percebidos como dois lados da mesma moeda. Torna-se possível quando jovens, saindo da posição passiva, passam a assumir o seu papel, percebendo-se como possíveis agentes de mudança social.

\footnotetext{
+ Trabalho apresentado no V Congresso Brasileiro de Saúde Coletiva - Saúde, Justiça e Cidadania. Brasília: ABRASCO, Universidade de Brasília; 2003.

* Doutoranda pelo Departamento de Epidemiologia da Faculdade de Saúde Pública da USP. Bolsista CNPq - Processo: 140097/2005-8. Rua: Arthur Corradi, 120, $3^{\circ}$ andar - Vila Duzzi, SBC. SP. Cep: 09725-240. Fone: 4125- 8619/ 41216499 - e-mail: maconti@usp.br

** Especialista em Gestão Escolar e Professor do Ensino Médio do Inst. de Ensino Jardim-Pueri-Domus-Sto. André-SP.

*** Graduado em Letras e Relações Públicas e Prof. do Ensino Médio do Inst. de Ensino Jardim-Pueri-Domus-Sto. André-SP.
} 
Esta preocupação está presente nas propostas de Morin ${ }^{1}$, referindo-se à missão antropológica do novo milênio como o necessário desenvolvimento da Ética, da Solidariedade, da Compreensão, do Respeito ao outro e a si próprio, do Ensinar a ética do gênero humano, enfim trabalhar para a humanização da humanidade. Nesta direção, o processo educacional torna-se imperativo como uma das possibilidades mais ricas para o alcance de tais metas.

Há tempos o espaço escolar deixou de priorizar unicamente a aquisição do conhecimento "bancário" como sinalizado por Freire 2 . O compromisso social da Instituição - Escola abre novas frentes de relações fortalecendo a relação com a comunidade. Segundo Dalben ${ }^{3}$ a principal riqueza da escola hoje refere-se à possibilidade de trabalhar com a diferença enquanto uma categoria capaz de produzir conhecimento e promover o desenvolvimento do próprio sujeito.

Dentro deste espírito, uma equipe de professores de uma Escola da Rede Particular de Ensino do ABC Paulista, integrando nas intenções pedagógicas da grade curricular a educação política, desenvolveu um estudo de campo envolvendo a conceituação de cidadania e democracia, culminando com o desenvolvimento de atividades na Câmara dos Vereadores do município de Santo André, no período do segundo semestre do ano de 2002.

Os atores sociais envolvidos neste processo foram compostos pelos alunos do Ensino Médio, totalizando 100 jovens; a equipe discente, com cinco professores de áreas específicas e duas coordenadoras do Cerimonial da Câmara dos Vereadores. Estes jovens caracterizavam-se pelo comprometimento com o ensino acadêmico no período da manhã, com atividades optativas como modalidade esportiva, teatral ou social como encontros informais com colegas, no período da tarde. Eram jovens com perfil de dedicação exclusiva aos compromissos escolares, bem como aos compromissos relacionados ao mesmo.

O contato inicial realizou-se por meio da equipe discente à Câmara dos Vereadores, atendendo as exigências para a efetivação da atividade, com a apresentação de um projeto inicial de trabalho e termos de autorização assinados pelos pais e/ou responsáveis bem como pela representante da Escola, na figura da Coordenadora do Ensino Médio.

\section{O caminho percorrido}

A atividade transcorreu em dois grandes momentos: a preparação teórica-conceitual e sensibilização do grupo de alunos, desenvolvidas nas disciplinas de Assembléia de Classe, História, Filosofia e Português, e a visita à Câmara dos Vereadores.

A preparação teórica compôs-se de pesquisas, construção da cidade ideal, do perfil ideal de vereador e a elaboração de projetos de leis que beneficiariam a cidade. O entendimento dos conceitos de cidadania e democracia fica incompleto quando não trabalhado como uma construção humana num determinado espaço e num determinado tempo histórico; tal construção, por sua vez, só pode ser assimilada e compreendida com a participação do aluno sobre sua realidade, seja ao percebê-la ou na intervenção consciente, não havendo exercício democrático sem a participação popular.

Neste sentido, tirar o estudante de seu conforto habitual é ação fundamental para que possa conhecer e entender os problemas, das mais variadas origens, em seu entorno e principie, subjetivamente, a elaborar um certo incômodo que poderá vir a ser o motor de toda sua retórica e ação política.

A historiografia da construção democrática, sobretudo a relacionada com a Antigüidade Clássica, ilumina e esclarece as causas e a necessidade da Democracia e como nasceu com esta um novo significado para a participação popular (considerando, inclusive, 
a ampliação do termo povo/popular através dos séculos).

A observação do mundo e a sua conseqüente transformação são medidas que comprometem os sujeitos a um objetivo maior do que eles mesmos: a permanente consciência que uma coletividade só existe quando todos nela se beneficiam e por ela agem. Deste modo, foram desenvolvidas atividades exploratórias e informativas sobre a constituição das cidades na História, inicialmente as orientais e a concepção da cidade ocidental, da arquitetura dos castelos e muralhas à urbanização e higiene social no final do século XIX e século XX.

Paralelamente, desenvolveu-se a construção de uma cidade ideal, partindo do seguinte princípio: se cada um tem uma cidade ideal para si - realmente apenas no plano das idéias - , então a que existe não tem os elementos constitutivos esperados. Todavia, esse "vir a ser" só será possível mediante uma ação política dos sujeitos sociais, sendo, aqui possível esclarecer, inclusive, a quem tal cidade ideal viria a abrigar. Neste momento, o trabalho pedagógico encontrou sua catarse, uma vez que o aluno olhou para si e num processo mais profundo de reflexão encontrou alguns fragmentos de seu repertório de valores para entender a si e seu ser no mundo, ou seja, os valores que fundamentam suas ações "dizem" muito.

Nesta direção, Freire ${ }^{4}$ aponta a necessidade da construção de um saber embasado na criticidade, no respeito aos saberes dos educandos, na reflexão crítica acerca da prática e, principalmente, que o ato de educar referese a uma forma de intervenção no mundo. Para o grupo, mudar o mundo passou a fazer sentido e procurar resoluções e propostas para a coletividade resgatar o bem viver - sendo que todos devem usufruir o bem viver - foram basicamente as questões colocadas nos projetos de lei dos vários vereadores eleitos entre os próprios alunos.

Antes, porém, levantou-se o perfil do representante do povo, resgatando o papel da autoridade diferenciada do "representante" autoritário. Em um cartaz fixado na sala de aula, os alunos colocaram qualidades que um representante deve ter. A partir daí procuraram, entre os colegas, aqueles que, por suas ações escolares, estariam mais próximos ao perfil elaborado - lembrando que o critério não foi aproveitamento escolar, mas sim do entendimento da vida social saudável, baseada numa rede ampla de "co-afetividades" e autêntico coleguismo.

Especificamente na disciplina "Assembléia de Classe", que tem por objetivo colocar o aluno em contato com sua realidade escolar, colaborando, pelo diálogo, na construção de uma escola mais democrática - os alunos foram orientados a eleger democraticamente, entre seus colegas, 21 representantes que assumiriam o papel de vereador.

Esta disciplina como prática educativa, segundo Rovira ${ }^{5}$, caracteriza-se como um elemento essencial na dinâmica de uma escola democrática e também como um instrumento institucional de educação de valores. Cumpre papel informativo tanto para educadores como educandos, de análise dos fatos e de decisão e organização do que ser feito, almejando a regulação da classe em sua convivência.

Dentro deste espírito de Assembléia de Classe, os alunos utilizaram os conceitos desenvolvidos na disciplina de História, sobre as características ideais para o exercício da função pública, no caso, a função de vereador, com os alunos eleitos exercendo a função da representação da comunidade, por meio da expressão e defesa dos projetos e leis pré-elaborados. Desenvolveram pesquisas em sites organizacionais sobre as necessidades e urgências dos bairros, sendo os temas mais evidenciados: violência; - problemas de infra-estrutura (lixo, água encanada, crescimento desordenado de favelas); - educação (direito de todo cidadão).

A partir das necessidades elencadas na 
disciplina de História, os alunos desenvolveram projetos de lei com o intuito de trazer melhorias para a cidade. As devidas correções gramaticais foram desenvolvidas na disciplina de Português. Concomitantemente a esse processo, em Filosofia, discutiam-se temas referentes ao exercício da cidadania e às dificuldades vividas para seu pleno exercício.

No dia em que antecedeu a saída temática, ainda na disciplina Assembléia de Classe, os alunos foram divididos em dois grupos, entre os vereadores eleitos e os demais, ocorrendo uma sensibilização em diferentes momentos. Para os vereadores, após a leitura dos projetos de lei, desenvolveu-se uma dinâmica de argumentação, ponderando-se as reais necessidades da região bem como a importância da expressão clara por parte dos vereadores a respeito das idéias a serem defendidas. Para os demais, o enfoque deu-se na importância da compreensão para o acompanhamento, bem como na exigência de coerência por parte dos alunos eleitos.

Ocorreu desta forma a preparação dos alunos para exposição sobre os projetos de leis por eles elaborados e a construção de argumentos e contra-argumentos. Objetivou-se o estímulo à investigação social e à identificação das problemáticas ao qual a cidade estava envolvida por meio da descrição dos fatos, de sua classificação e, por fim, do movimento interpretativo.

Segundo Morin ${ }^{1}$, um dos saberes necessários à educação do futuro refere-se aos princípios do conhecimento pertinente; desta forma, a contextualização torna-se essencial. Fazse necessário situar as informações, bem como os dados em seu contexto para que adquiram sentidos. A contextualização sociocultural, por meio da comparação das problemáticas atuais e passadas, do posicionamento crítico diante de fatos presentes a partir da interpretação e análise de suas relações com o passado, referemse a um dos pontos abordados nos Parâmetros Curriculares Nacionais (PCNs), bem como a necessidade ao estímulo da investigação e compreensão. Sendo assim, no presente trabalho, vivenciou-se uma aproximação da construção da identidade pessoal e histórica do aluno, a partir do reconhecimento do papel do indivíduo com a prática do exercício da cidadania.

O estudo de campo transcorreu na Câmara dos Vereadores sob a orientação das coordenadoras do cerimonial - responsáveis pelo projeto que incentiva o ensino do cotidiano da representação política municipal para as escolas da. Houve a simulação de uma sessão oficial e, nessa oportunidade, foram apresentados, seguindo-se as exigências do protocolo, os projetos de leis, sua defesa e crítica.

Os alunos participaram ativamente da sessão, conhecendo a rotina do poder legislativo municipal, por meio do exercício democrático - base fundamental para a educação política. Segundo os PCNs, o Ensino Médio deve orientar a formação do aluno nas direções do aprender a conhecer, aprender a fazer, aprender a conviver e aprender a ser, proposta esta apontada pela Comissão Internacional sobre Educação para o Século XXI, da UNESCO.

Neste contexto, almeja-se que o espaço educacional busque formas de transformar indivíduos em pessoas plenas para o exercício da cidadania, cujos saberes se revelem em competência cognitivas e sócio-afetivas, bem como nos valores de sensibilidade e solidariedade necessários ao aprimoramento da vida humana.

Para a Lei de Diretrizes e Bases, promulgada em Dezembro de 1996, o processo educacional deve primar pelo aprimoramento do educando como pessoa humana, incluindo a formação ética e o desenvolvimento da autonomia intelectual e do pensamento crítico.

\section{POSSÍVEIS CONCLUSÕES E SUGES- TÕES}

Com o presente trabalho, pode-se concluir que uma das metas principais da educação 
do futuro - a educação cidadã - se cumpriu. $\mathrm{O}$ aluno teve contato com a teoria política e análise de sua realidade social imediata, chegando a uma idéia da necessidade de uma participação social e política consciente e da responsabilidade social de todos nós frente às demandas vigentes em uma sociedade em constante transformação.

Sugere-se o desenvolvimento de ativi- dades semelhantes à apresentada, visto sua importância na construção da consciência cidadã dos indivíduos inseridos neste processo. Assim, mais alunos poderão ter acesso a uma dinâmica educacional que zela pelo conhecimento educacional embasado no agir, na apreensão da realidade, na autonomia do educando, no diálogo, enfim na práxis da ação democrática.

\begin{abstract}
The concept of citizenship seen as having rights and duties and assuming social responsibility related to transformation begins when rights and duties are seen together. This can occur to be possible when young people leave the passive position to play the role of a changer. A team of teachers from a private school adding political education in their curriculum developed a study involving the concepts of citizenships and democracy, together with the work in the local city council. Around 100 senior high school students from the first grade shared all the legislative routine exercising their democracy - the fundamental standard for a political education. In that matter this team fulfilled one of its main goals: the citizenships education. The student was in contact with the political theory and the analyses of its social reality, finding out the need of a major social participation and a conscious sense of politics and mainly the social responsibility that everybody has to face when we have all the constant changes of a society.
\end{abstract}

Key words: Interdisciplinary project. Political education. Citizenship education.

\section{REFERÊECIAS}

1. Morin E. Os sete saberes necessário à educação. $5^{\mathrm{a}}$ ed. São Paulo: Cortez; 2002

2. Freire P. Pedagogia do oprimido. Rio de Janeiro: Paz e Terra; 1974.

3. Dalben AMILF. A nova escola: um desafio do terceiro milênio. In: Associação Brasileira de Adoles- cência \& Associação Mineira de Adolescência. Ética e Cidadania. Belo Horizonte: ASBRA/AMA; 2000.

4. Freire P. Pedagogia da autonomia - Saberes necessários à prática educativa. $30^{\mathrm{a}}$ ed. São Paulo: Paz e Terra; 1996.

5. Rovira JMP. Como hacer escuelas democráticas? Educação e Pesquisa 2000; 26(2): 55-69. 